Proceeding of the $1^{\text {st }}$ ICEENG conference, 24-26 March, 1998 ECH.6 597

MILITARY TFCHNIC:AL COLLEGE

CAIRO-EGYPET

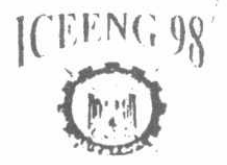

FIRST INTERNATIONAL CONF. ON

ELECTRICAL ENGINEERING

\title{
Current Disruption in Coaxial Discharge
}

\author{
I.. A. Mehanna, A.S. Girgis, and H.F. El Afifi, \\ Military Technical College \\ Cairo, Egypt
}

\begin{abstract}
Quasi-disruption of the discharge current has been occurred in an electrode discharge system. The discharge takes place between two T-shaped electrodes, a copper central cylindrical rod and a molybdenum cylindrical transverse rod. The capacitor bank used has $52 \mathrm{~kJ}$. maximum stored energy, which consists of two capacitors $680 \mu \mathrm{F}$ capacitance each, triggering spark gap system, micro processor control system, and the power supply. The discharge current was a fast rising single pulse one, with a peak value at $500 \mu \mathrm{s}$, then it decayed exponentially in $7.5 \mathrm{~ms}$. The peak discharge current increases linearly with the charging potential of the capacitor banks, which was $14 \mathrm{kA}$ at $15 \mathrm{kV}$. The discharge current disruption starts early with the increasing of the capacitor bank charging voltage in a linear relation. This indicates that the diamagnetic effect of the plasma is the main source of such disruption.
\end{abstract}

\section{Key words}

Plasma, Coaxial discharge, Diamagnetic, Current distuption. 


\section{Introduction}

Current distuption has been observed in T-tube discharge when a current of 20 $k \wedge$ with rise time of 20 M.s. flows between two annular electrodes with a spacing of $10 \mathrm{~mm}$. [1]. At the moment of the current disruption a propagation of a fast enrergy wave packet pulse is detected. Such wave propagates without noticeahle dissipate interaction but it has a fast destructive behavior producing a shock wave. Plasma current disruption occurs in tokamak plasma and this has heen investigated in relation with hydro-magnetic instability modes $[2,3]$. For axial srmmetric discharge between two electrodes the plasma is pinched to a small column and the plasma possesses a diamagnetic behavior. In z-pinch it has heen ohserved that an induced current loop at the outer surface of the pinched columm[4]. This is referred to the diamagnetic effect [5], which induce hack c.m.f. to give rise to a reverse current. Current disruption occurs when the hack e.m.f. is in the order of the discharge potential at that moment.

\section{Experimental Arrangements}

A schematic diagram of the system is shown in fig.1. The device consists of the plasma source, expansion chamber, capacitor hank, triggering system, diagnostic tools. data acquisition system, and micro-processor control system. The plasma source is an electrode type consists of T-shaped electrodes. The axial electrode is a cylindrical brass rod, $25 \mathrm{~mm}$. diameter, with hemi-spherical head shape where the discharge takes place. The transverse electrode is a cylindrical molybdenum rod with $6 \mathrm{~mm}$. diameter. The plasma source is placed in a steel cylindrical chamber 2.6 liter volume. The system is evacuated by a rotary pump.

The capacito hank consists of two Maxwell capacitors, $9 \mathrm{kV}$ maximum charging voltage, each with $680 \mu \mathrm{F}$ capacitance. The triggering system consists of a spark gap switch and a trigger pulse generator. The spark gap switch is a field distortion triggatron type. It consists of three electrodes, the two main electrodes are made from graphite and a tungsten pin trigger electrode. $A$ trigger pulse is fed from a trigger generator to the pin electrode .

Diagnostics available are the current measurements by Rogowsky coil, pressure pizo electric ransducer, and (CD) camera linked to a mono-chromator for spectroscopic measurements. The diagnostic tools are linked with data acquisition sy: $1 \mathrm{em}$. The system is fully controlled hy a micro-processor. 
Proceeding of the $1^{\text {st }}$ ICEENG conference, 24-26 March, 1998

ECH.6599

\section{Experimental Results and Discussion}

The discharge current has been measured by the Rogowsky coil. Figure 2 shows the discharge current for $10 \mathrm{kV}$ capacitor bank charging voltage and for initial air pressure of 3 Torr.

This figure shows that the current reaches $11 \mathrm{kA}$ in $0.5 \mathrm{~ms}$, then decays exponentially. The analysis of the current shape showed that it follows the relation:

$$
I=I_{0} \sin (1) t
$$

in the start of the discharge, then it decays according to the relation :

$$
I=I_{0} \exp (r / 2 I) t,
$$

where $l$ is the circuit induct area and $r$ is the circuit resistance. When the charging voltage increased from 10 to $15 \mathrm{kV}$ the discharge current increased linearly. lig. ?

When the initial gas pressure is reduced to I Torr the discharge current shows a different behavior where a cut off of the current occurs at the different charging voltages, fig.4. It is clear from that figure that the current disruption occurs at different times from the start of the discharge according to the capacitor hank charging voltage. The relation of the time of occurrence of the current disruption and the charging voltage is shown in fig.5. It has been observed that with the increase of the charging voltage the current disruption occurs earlier. This is with agreement with the theoretical proposal [1] which referred the disruption to the plasma diamagnetic effect.

\section{Conclusion}

Current distuption has heen observed in an electrode discharge. The discharge system consists of two cylindrical rod electrodes in a T-shape configuration where the axial rod is a brass and the transverse one is made from molybdenum.

The discharge current was fast increasing with rise time of $0.5 \mathrm{~ms}$. then it decays exponentially. The pak current value was $16 \mathrm{kA}$. for $15 \mathrm{kV}$. capacitor bank charging voltage. Current disruption occurs when the initial gas pressure is reduced to 1 Torr for three charging voltage of the capacitor bank, $10,12.5$, $15 \mathrm{kV}$. 
Proceeding of the $1^{\text {st }}$ ICEENG conference, 24-26 March, 1998

ECH $6 ; 600$

It has been found that the current disruption time is dependent on the discharge current. It occurs earlier for higher current where the plasma temperature reaches certain value to be diamagnetic.

\section{Reforences}

(1) Masom M.M., Bomham M.A. Sharkawy W. and Saudy A.H.

7. Naturforsch vol. 42a, 120)(1986).

[2] Mererhkin V.G.

Fizika Plasmy vol. 4. 275 (1978)

[3] Waddel R.V., Carreras B.. Hicks H.R., and Holmes 7. A.

Phys. Fluids vol. 22, 897 (1979)

[4] Jones R. I. , and Silawatshani C.

Plasma Physics, vol. 22, 501 (1980)

[5] Mohamed W.II.G.

M. Sc. thesis, $\Lambda$ in shams Iniversity(1997) 


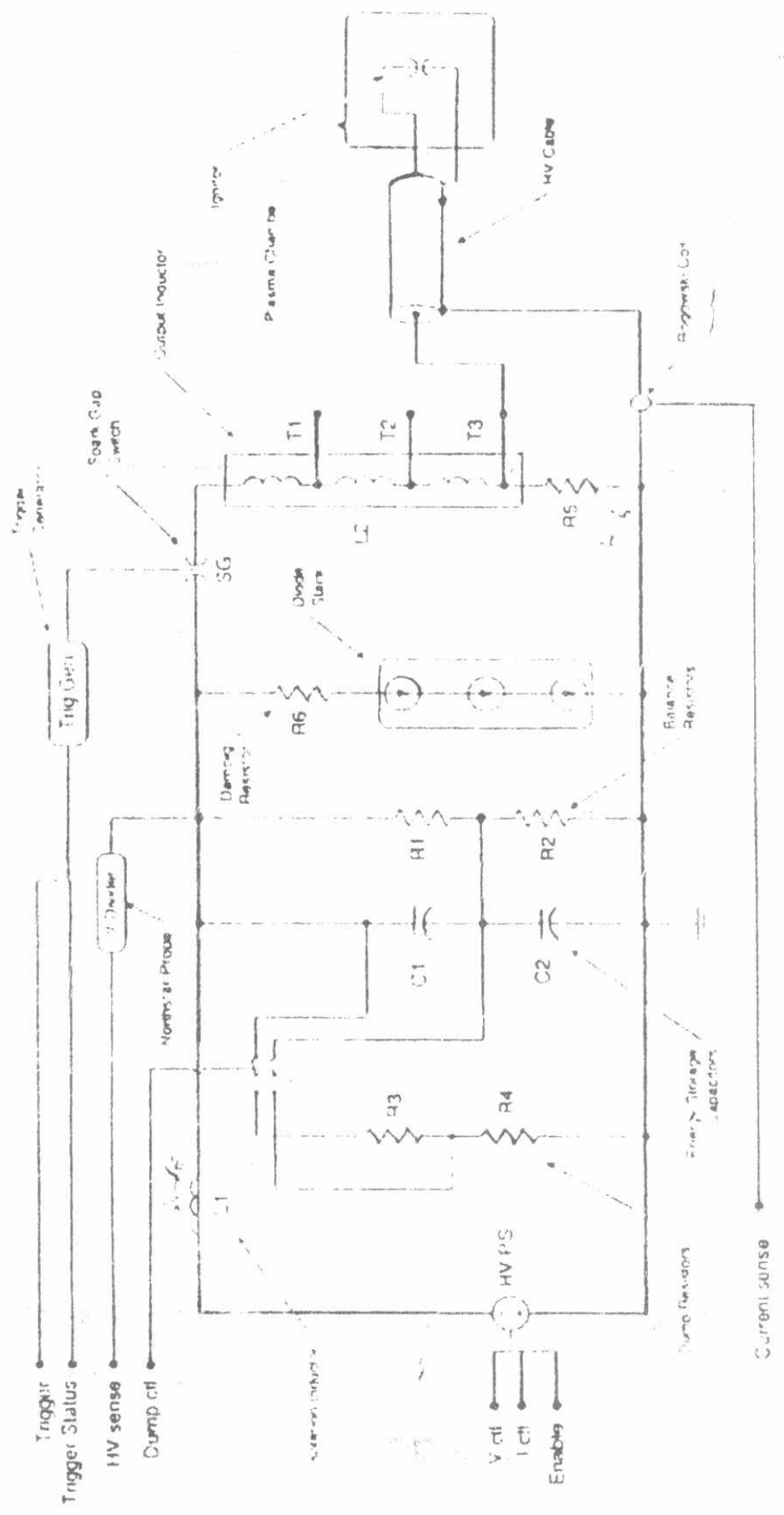

fig(1) Schematic diagram of the simplified circuit of the plasma lab 


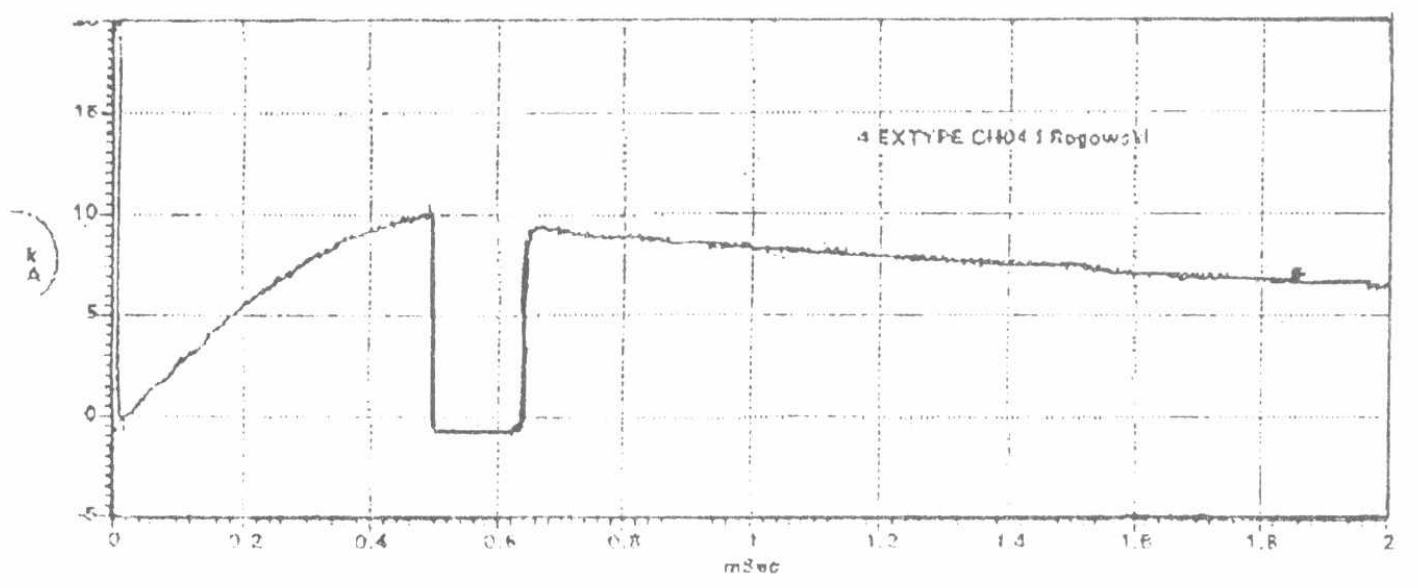

Fig (2) The discharge current measured hy the Rogowsky coil at $10 \mathrm{kV}$ charging voltage

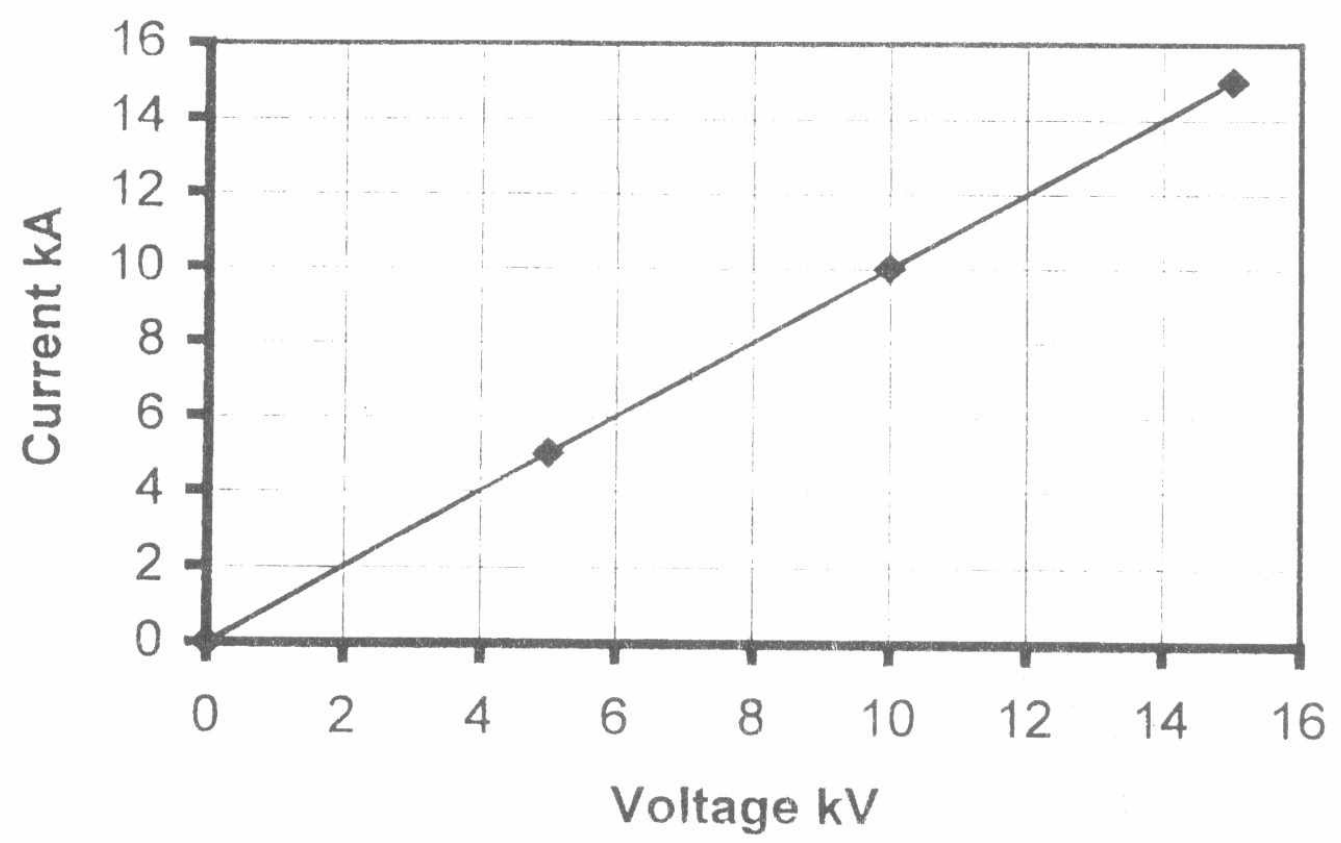

Fig (3) Relation between the charging voltage and discharge current 
Proceeding of the $1^{\text {st }}$ ICEENG conference, 24-25 March. 1998

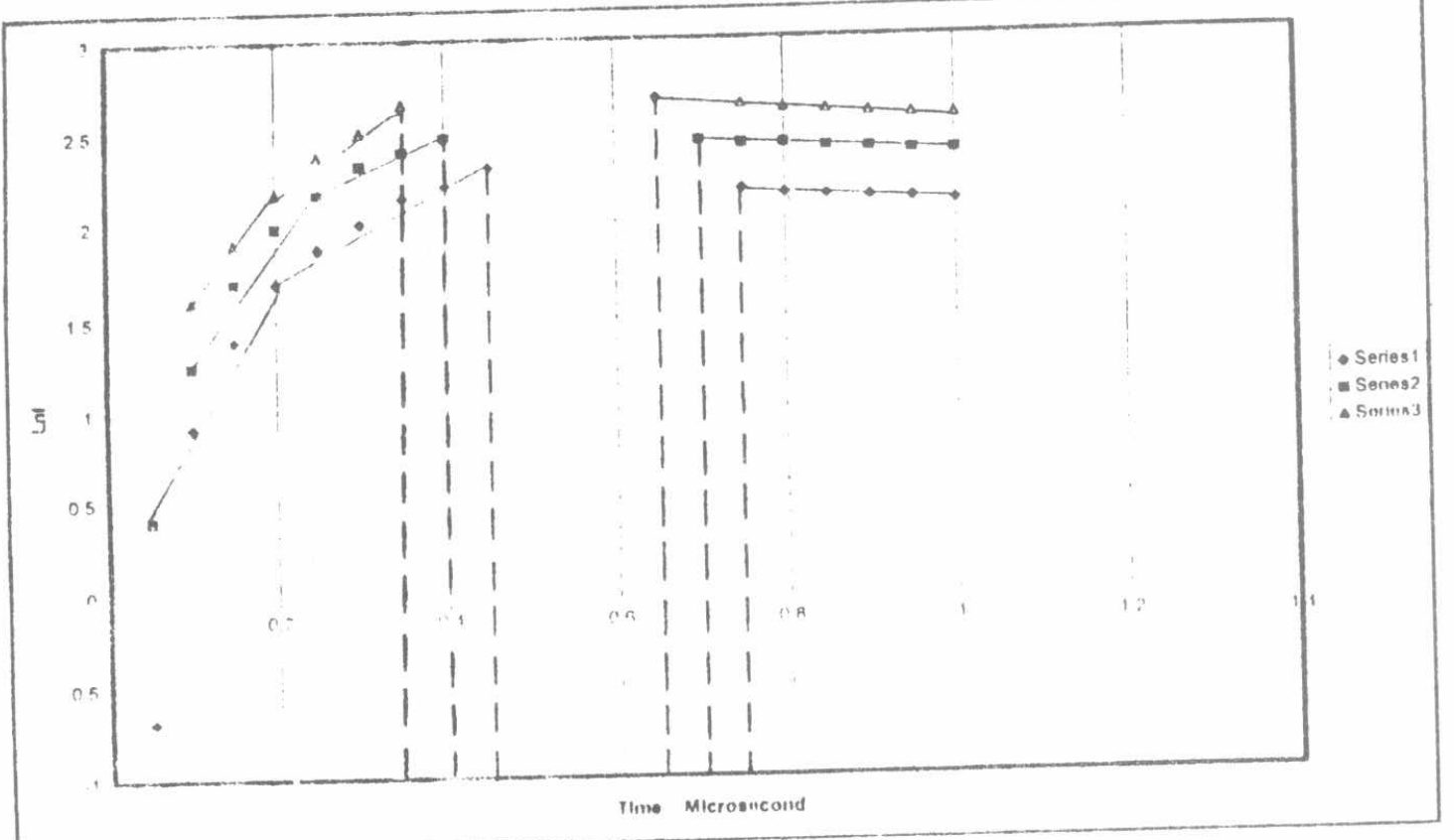

Fing(4) The relation hetween I n I at $10.12 .5,15$ charging voltages with lime

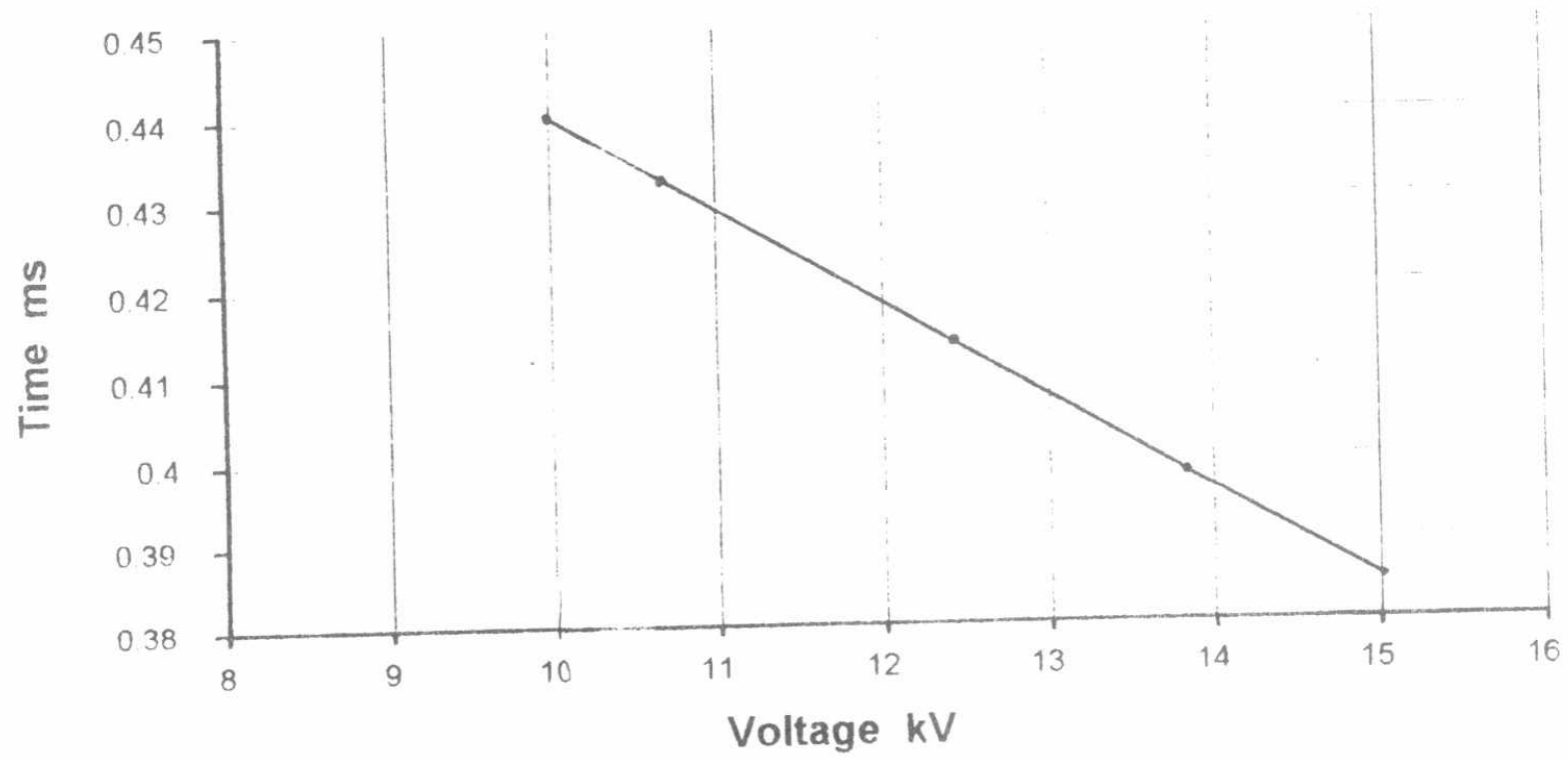

Fig (5) Relation between the rise time and the corresponding applied voltage 
